\title{
Necessity of organized low-dose computed tomography screening for lung cancer: From epidemiologic comparisons between China and the Western nations
}

\author{
Hong-Feng Gou ${ }^{1}$, Yang Liu ${ }^{2,}{ }^{*}$, Tian-Xia Yang ${ }^{3}$, Cheng Zhou ${ }^{4,5,6}$ and Xin-Zu Chen ${ }^{7}$ \\ ${ }^{1}$ Department of Medical Oncology, Cancer Center, State Key Laboratory of Biotherapy, West China Hospital, Sichuan \\ University, Chengdu, China \\ ${ }^{2}$ West China School of Public Health, Sichuan University, Chengdu, China \\ ${ }^{3}$ Department of Nuclear Medicine, West China Hospital, Sichuan University, Chengdu, China \\ ${ }^{4}$ Translational Radiation Oncology, National Center for Tumor Diseases (NCT), German Cancer Research Center (DKFZ), \\ Heidelberg, Germany \\ ${ }^{5}$ Heidelberg Ion Therapy Center (HIT), Department of Radiation Oncology, University Heidelberg Medical School, Heidelberg, \\ Germany \\ ${ }^{6}$ German Consortium for Translational Cancer Research (DKTK), German Cancer Research Center (DKFZ), Heidelberg, \\ Germany \\ 7 Department of Gastrointestinal Surgery, West China Hospital, Sichuan University, Chengdu, China \\ * These authors have contributed equally as a co-first author \\ Correspondence to: Xin-Zu Chen, email: chen_xz_wch_scu@126.com \\ Keywords: lung cancer; screening; low-dose computed tomography; epidemiology; mortality \\ Received: March 26, $2016 \quad$ Accepted: September 13,2016 Published: October 01, 2016
}

\section{ABSTRACT}

Objectives: To compare the proportion of stage I lung cancer and population mortality in China to those in U.S. and Europe where lung cancer screening by lowdose computed tomography (LDCT) has been already well practiced.

Methods: The proportions of stage I lung cancer in LDCT screening population in U.S. and Europe were retrieved from NLST and NELSON trials. The general proportion of stage I lung cancer in China was retrieved from a rapid meta-analysis, based on a literature search in the China National Knowledge Infrastructure database. The lung cancer mortality and prevalence of China, U.S. and Europe was retrieved from Globocan 2012 fact sheet. Mortality-to-prevalence ratio (MPR) was applied to compare the population survival outcome of lung cancer.

Results: The estimated proportion of stage I lung cancer in China is merely $\mathbf{2 0 . 8} \%$ among hospital-based cross-sectional population, with relative ratios (RRs) being 2.40 (95\% CI 2.18-2.65) and 2.98 (95\% CI 2.62-3.38) compared by LDCTscreening population in U.S. and Europe trials, respectively. MPR of lung cancer is as high as 58.9\% in China, with RRs being 0.46 (95\% CI 0.31-0.67) and 0.58 (95\% CI 0.39-0.85) compared by U.S. and Europe, respectively.

Conclusions: By the epidemiological inference, the LDCT mass screening might be associated with increasing stage I lung cancer and therefore improving population survival outcome. How to translate the experiences of lung cancer screening by LDCT from developed counties to China in a cost-effective manner needs to be further investigated.

\section{INTRODUCTION}

The stage of the lung cancer is an important prognostic factor, and therefore the opportunity for curative treatment and long-term survival outcome declines with more advanced diseases [1,2]. By now, there is still no definitive biomarker or genetic factor for prediction or early diagnosis of lung cancer [3]. Low-dose 


\begin{tabular}{|l|l|l|l|l|}
\hline Table 1: A pooling estimate on the proportion of stage Uung cancer among Chinese population during 2012-2014. \\
\hline Study & Stage I (n) & Sample $(\mathrm{N})$ & Proportion $(95 \% \mathrm{CI})$ & COPD status \\
\hline Chen R, 2014 & 165 & 816 & $20.2 \%(17.6 \%-23.1 \%)$ & Any \\
\hline Lou J, 2014 & 294 & 1329 & $22.1 \%(20.0 \%-24.4 \%)$ & Any \\
\hline Li LX, 2013 & 0 & 110 & $0.5 \%(0.0 \%-6.8 \%)$ & Prevalent \\
\hline Sun HB, 2013 & 24 & 100 & $24.0 \%(16.6 \%-33.3 \%)$ & Prevalent \\
\hline Yi ZM, 2013 & 0 & 42 & $1.2 \%(0.1 \%-16.0 \%)$ & Prevalent \\
\hline Bo XX, 2012 & 2 & 48 & $4.2 \%(3.4 \%-5.0 \%)$ & Prevalent \\
\hline Lin XF, 2012 & 44 & 105 & $41.9 \%(32.9 \%-51.5 \%)$ & Prevalent \\
\hline Wang Y, 2012 & 6 & 35 & $17.1 \%(7.9 \%-33.3 \%)$ & Prevalent \\
\hline $\begin{array}{l}\text { Pooling estimate } \\
\text { (random effect)* }\end{array}$ & 535 & 2585 & $20.8 \%(15.3 \%-27.5 \%)$ & \\
\hline $\begin{array}{l}\text { Abbreviations: CI, confidence interval; COPD, chronic obstructive pulmonary diseases. } \\
* \text { Heterogeneity test: I-square }=84.1 \%, p<0.001 .\end{array}$ \\
\hline
\end{tabular}

\begin{tabular}{|c|c|c|c|c|c|c|}
\hline Study & Sample & $\begin{array}{l}\text { Male } \\
\%(95 \text { CI) }\end{array}$ & $\begin{array}{l}\text { Age (yrs) } \\
\text { mean } \pm \text { SD (range) }\end{array}$ & \begin{tabular}{|l|} 
Current or \\
former smoker \\
$\%(95$ CI)
\end{tabular} & $\begin{array}{l}\text { SCLC } \\
\%(95 \text { CI })\end{array}$ & $\begin{array}{l}\text { SCC } \\
\%(95 \text { CI })\end{array}$ \\
\hline Chen R, 2014 & 816 & $66.3(66.2-66.4)$ & $56.8 \pm 2.6(24-75)$ & $67.2(67.0-67.3)$ & $47.4(47.3-47.5)$ & $39.3(39.2-39.5)$ \\
\hline Lou J, 2014 & 1329 & $74.6(74.6-74.7)$ & $58(26-81)$ & 1 & $26.5(26.4-26.6)$ & $53.1(53.0-53.2)$ \\
\hline Li LX, 2013 & 110 & $80.0(79.3-80.7)$ & $58.9 \pm 10.8(40-85)$ & $92.7(92.3-93.2)$ & $10.9(10.4-11.5)$ & $37.3(36.4-38.1)$ \\
\hline Sun HB, 2013 & 100 & $71.0(70.1-71.9)$ & $69(56-82)$ & $82.0(81.2-82.8)$ & $11.0(10.4-11.6)$ & $46.0(45.0-47.0)$ \\
\hline Yi ZM, 2013 & 42 & $76.2(74.2-78.2)$ & $64.5(45-81)$ & $85.7(84.1-87.3)$ & $14.3(12.7-15.9)$ & $66.7(64.5-68.9)$ \\
\hline Bo XX, 2012 & 48 & $91.7(90.5-92.8)$ & $73.6(56-89)$ & $91.7(90.5-92.8)$ & $4.2(3.4-5.0)$ & $47.9(45.9-50.0)$ \\
\hline Lin XF, 2012 & 105 & $88.6(88.0-89.2)$ & $65.0 \pm 8.5$ & $81.9(81.2-82.6)$ & $9.5(9.0-10.1)$ & $49.5(48.6-50.5)$ \\
\hline Wang Y, 2012 & 35 & $77.1(74.8-79.5)$ & $63.7 \pm 6.7(54-76)$ & $88.6(86.8-90.4)$ & $20.0(17.8-22.2)$ & $45.7(42.9-48.5)$ \\
\hline
\end{tabular}

computed tomography (LDCT) for lung cancer screening is recommended as a promising approach to reducing mortality from lung cancer by NLST and NELSON trials in U.S. and Europe respectively [4, 5]. These trials found that LDCT screening was able to significantly increase the proportion of stage I diseases among detected lung cancer. Consequently, the overall survival of LDCT screening population may be obviously improved compared to population with conventional chest X-ray screening or without screening. Clinical practice guidelines also recommended the LDCT screening in the high-risk subpopulation [6].

In China, lung cancer is always the leading cause of cancer death [7]. However, LDCT has not been applied as a preferred screening approach to lung cancer in China. The necessity of LDCT for lung cancer screening in mass health examination needs to be underlined in China. Therefore, to provide epidemiological evidence, we compare the proportion of stage I lung cancer and population mortality in China to those in U.S. and Europe, where LDCT screening for lung cancer has been already well practiced.

\section{RESULTS}

Meta-analysis based on 2,585 patients from 8 eligible studies demonstrates that the general proportion of stage I lung cancer in China is merely $20.8 \%$ (Table 1). The patient characteristics are shown in Table 2. Comparing the proportions in LDCT-screening populations from NLST and NELSON trials to that in China, the RRs for proportions of U.S. or Europe to China are $2.40(95 \%$ confidence interval $[\mathrm{CI}] 2.18-2.65)$ and 2.98 (95\% CI 2.62-3.38), respectively ( $<<0.0001)$ (Table $3)$. On the other hand, despite of a lower prevalence, the MPR of lung cancer is as high as $58.9 \%(95 \%$ CI $57.1 \%-$ $60.6 \%$ ) in China, compared to only $26.9 \%$ (95\% CI $26.1 \%-27.7 \%$ ) and $33.9 \%$ (95\% CI $32.6 \%-35.3 \%$ ) in U.S. and Europe, respectively (Table 3). The RRs for MPRs of U.S. or Europe to China are 0.46 (95\% CI $0.31-0.67)$ and 0.58 (95\% CI 0.39-0.85), respectively $(p<0.005)$.

\section{DISCUSSION}

The significantly higher MPR in China indicates the population survival outcome of lung cancer is apparently worse than that in U.S. and Europe. This unfavorable 


\begin{tabular}{|c|c|c|c|}
\hline Outcome & China & U.S. & Europe \\
\hline \multicolumn{4}{|l|}{ Stage I lung cancer } \\
\hline Proportion, $\%(95 \% \mathrm{CI}) \dagger$ & $20.8(15.3-27.5)$ & $50.0(49.9-50.1)$ & $61.9(61.5-62.3)$ \\
\hline RR of proportion $(95 \% \mathrm{CI})$ & Reference & $2.40(2.18-2.65)$ & $2.98(2.62-3.38)$ \\
\hline$p$ value (2-sided) & - & $<0.0001$ & $<0.0001$ \\
\hline \multicolumn{4}{|l|}{ Population mortality index } \\
\hline Mortality $\$$ & 32.5 & 28.6 & 24.0 \\
\hline Prevalence $\$$ & 55.2 & 106.4 & 70.7 \\
\hline MPR, \% $(95 \%$ CI $)$ & $58.9(57.1-60.6)$ & $26.9(26.1-27.7)$ & $33.9(32.6-35.3)$ \\
\hline RR of MPR $(95 \%$ CI $)$ & Reference & $0.46(0.31-0.67)$ & $0.58(0.39-0.85)$ \\
\hline$p$ value (2-sided) & - & 0.0001 & 0.0041 \\
\hline
\end{tabular}

situation in China may attribute to the lower proportion of stage I disease among detected lung cancers, compared to those LDCT-screening populations. These epidemiological findings imply the disadvantage in detecting early lung cancer in China is largely owing to default of nationwide organized screening programme for lung cancer, especially via LDCT mass screening.

Factually, in 2003, Ministry of Health (MOH), China has issued governmental outlines of China Cancer Prevention and Control Program (2004-2010) [8,9]. Lung cancer has been defined as one out of eight key malignancies requiring intensive prevention and control in China. The data between 2004 and 2010 reported by the National Cancer Registry, China [10-17] show the incidence and mortality of lung cancer tended to decline to certain extent (Figure 1), especially in the curves of mortality-to-incidence ratios (Figure 2). However, current screening and surveillance programmes for lung cancer are still implemented with loose organization in few major cities in China. Despite of previous efforts of cancer control, our findings demonstrate the population survival outcome of lung cancer is still poor, compared to western developed countries. It implies that it is necessary to find an efficient screening approach to increasing the proportion of early lung cancer and subsequently improving the population survival outcome of lung cancer.

Commonly, the health check-up examination for lung cancer in China is based on chest X-ray for many years. According to NLST trial, LDCT shows better performance for detecting early-stage lung cancer and is associated with decreased mortality from lung cancer [4]. By now, many Chinese hospitals attempt to practice LDCT for lung cancer screening during health check-up instead of traditional chest X-ray test. In the study of Zhang et al. [18], the detection rate of suspicious lesions (at least 1 non-calcified nodule with a diameter $\geq 4 \mathrm{~mm}$ ) in lung was
$9.9 \%$ among 2,251 asymptomatic participants. In the study of Tang et al. [19], the detection rate of lung cancer was $0.6 \%$ among 4,690 asymptomatic participants ( $\geq 40$ years old) from a medical institute in Beijing, and promisingly $76.0 \%$ of the detected lung cancers were stage I. In a retrospective study on surgical patients, Lai, et al. found the proportion of stage I lung cancer detected by LDCT was $14 \%$ higher than that by chest X-ray examination [20]. In China, initial experiences of screening lung cancer through LDCT were few, but those studies were able to repeat the capacity of increasing the proportion of stage I diseases among detected lung cancers.

Additionally, the healthcare insurance system has already been much advanced than before in mainland China, but the healthcare expenditure planned in the field of cancer screening and surveillance is still limited till now. First of all, the traditional chest radiography (with or without sputum cytology) has been denied as screening techniques for lung cancer [21, 22]. RCTs in the 1960s and 1970s found that chest X-ray screening did not reduce the mortality for high-risk individuals [23]. In contrast, current strong evidence showed that the LDCT mass screening can reduce lung cancer related and allcause mortality [24]. Actually, it is obviously difficult to establish a national whole-covering lung cancer screening programme based on LDCT at this moment in mainland China. On the other hand, extra expenditure in cancer screening and surveillance might obtain payoffs by preventing healthcare expenditure from adjuvant and palliative treatment for locally advanced and metastatic lung cancer patients, as well as controlling premature death from lung cancer and related disability-adjusted life year. Therefore, how to design a cost-effective screening programme for lung cancer based on LDCT must be a big question for public health administrations in mainland China [22]. Determination of high-risk population for 
screening and proper interval for surveillance would the two most important problems at the beginning of initial practice of LDCT mass screening among Chinese population. The access to the LDCT screening is also imbalanced between urban and rural areas [20, 25]. How to reduce the urban-rural imbalance of medical resources and healthcare insurance is another issue in designing a cost-effecitve screening program. Due to the uncertainty of feasibility for population-based LDCT screening in China, a demonstration program of lung cancer screening

\section{Lung cancer in China, 2004-2010}

(per 100,000 persons)

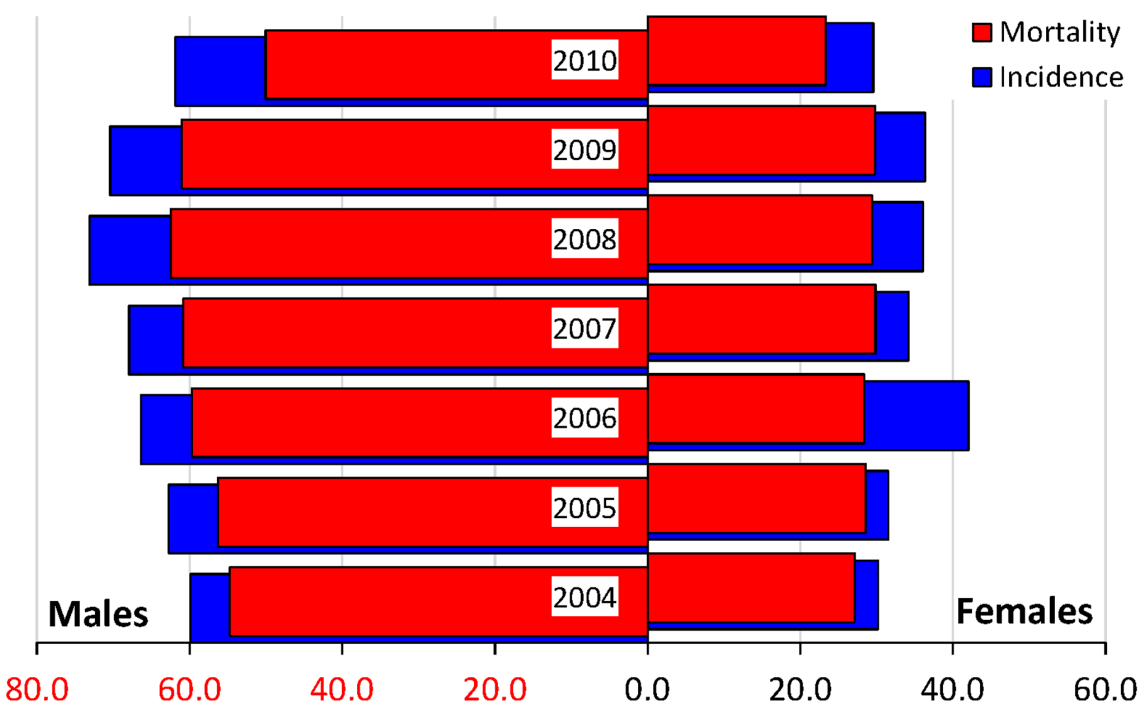

Figure 1: The crude incidence and mortality of lung cancer in mainland China, retrieved from annual reports of National Central Cancer Registry, China. Both the incidence and mortality tended to decrease till 2010.

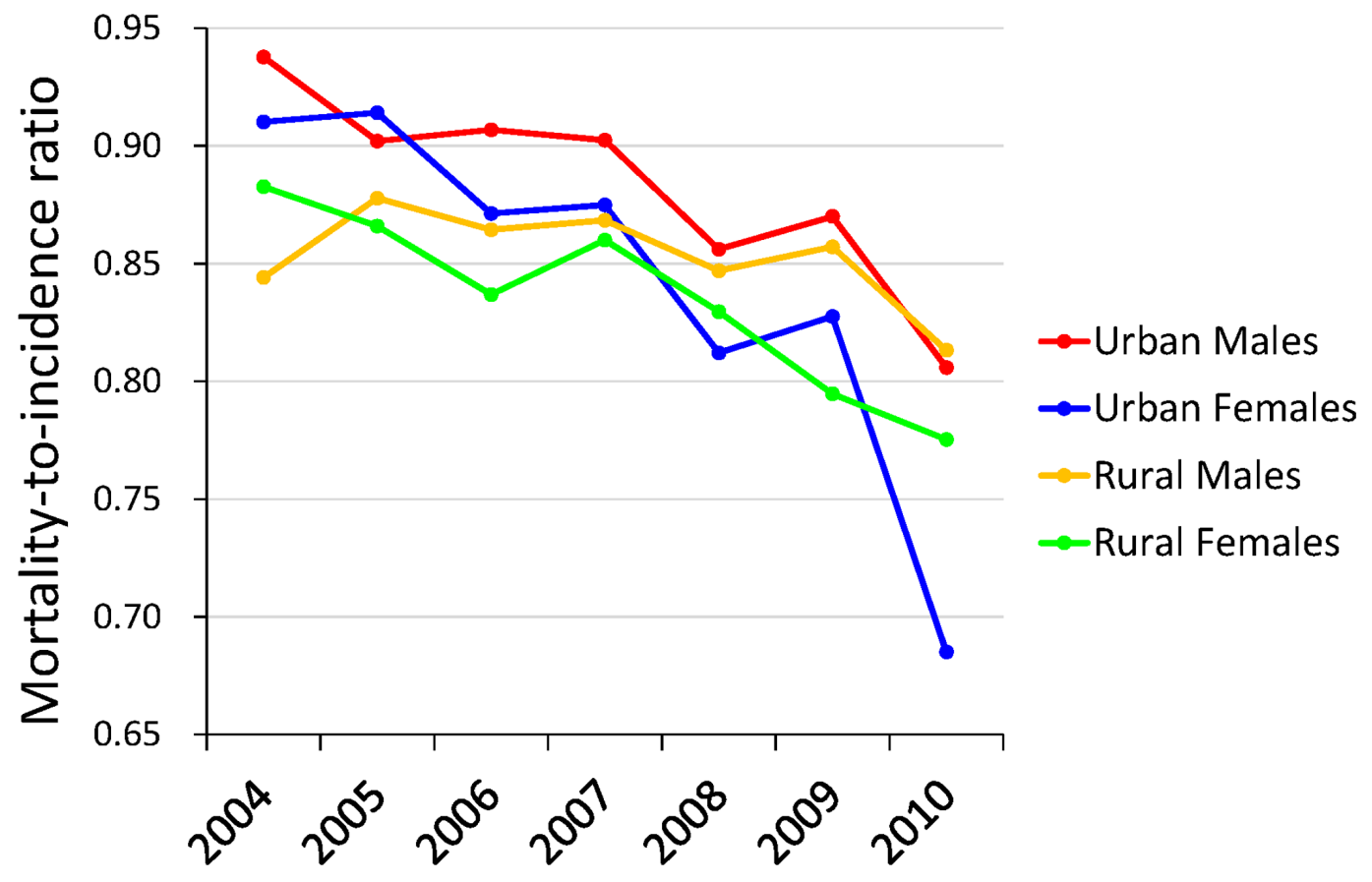

Figure 2: The curves of mortality-to-incidence ratios in mainland China. The ratios appeared to decline among any subpopulation, especially obviously for urban females. However, till 2010, the ratios were still higher than 0.65 and 0.75 among urban and rural females respectively, while they were always higher than 0.80 among males. 
was initiated in the 2010 [26]. High-risk individuals were enrolled in various Chinese centers, which aimed to provide opportunities to explore the feasibility of LDCT lung cancer screening in the Chinese setting [26].

The harm of LDCT massing screening also need consider with caution. Especially, radiation exposure, high false-positive rates, and the potential for overdiagnosis are regarded as major issues in the practice [27]. According to a systematic review, around $20 \%$ of screenees had positive findings indicating subsequent follow-up, but just $1 \%$ had lung cancer finally [28]. Currently, there is inadequate evidence to support the expansion of the LDCT mass screening into low-risk subpopulation [29]. The NLST trial was conducted among high-risk individuals of old age and heavy smokers, and demonstrated positive results [4]. The NLST participants with a negative LDCT screen at baseline had a lower incidence of lung cancer and lung cancer-specific mortality compared to all participants [30]. An extrapolation of NLST trial in Germany found $20 \%$ lower relative risk of lung cancer death among heavy smokers aged 55-74 years [31]. In a LDCT screening cohort in western China similar to participants in the NLST trial, Lei, et al. found the number of risk factors of lung cancer was associated with increasing detection rate of asymtomatic lung cancer [32]. Providing a strict design and conduction, the benefits of LDCT screening in highrisk populations for lung cancer may overweigh those harms [33]. However, there is no high-quality evidence based on Chinese population to define the specific highrisk subpopulation as screening candidates. China is a large market of tobacco consumption, and the society appears the phenomenon of population aging. Therefore, regarding the balance of benefits and harms, the criteria for screening candidates in the NLST trial is referrable to the health care system in China.

Moreover, the DANTE trial (based on a community setting) and the MILD trial didn't find confirmative results to support the LDCT mass screening against none screening $[34,35]$. In the aspect of a national plan, introducing some supplementary indicators for surveillance would be more cost-effective. In the practice, identificatoin of emphysema in LDCT scan is associated with an increased rate of lesion detection [36]. Namely, adding emphysema into the criteria for the more intensive LDCT surveillance may be an effecient approach to increasing detection rate of lung cancer. Pulmonary focal ground-glass opacities might frequently be identified by the LDCT screening, and partially associated with the high rate of false-positivity [37]. Jiang, et al. established a modified prognostic scoring system, which demonstrated a good performance in identifying benign and malignant opacities [37]. Development of a risk prediction model for lung cancer may discriminate high-risk from low-risk individuals based on the associations with demographic and environmental factors.[38]. Besides, a comprehensive lung cancer control plan in high risk areas should combine screening with tobacco control and health education, especially in population with low education level [39].

Therefore, recently, the lung cancer early detection and treatment expert group, appointed by the National Health and Family Planning Commission, launched a China national lung cancer screening guideline in the 2015 , based on current available high-quality evidence and protocol of lung cancer screening program conducted in rural China [40]. Annual LDCT screening joint with health education assisting smoking cessation is recommended for high risk individuals aged 50-74 years who have at least a 20 pack-year smoking history and who currently smoke or have quit within the past five years [40]. This guideline aims to translate the advancement through LDCT mass screening in western nations into increasing proportion of stage I-II lung cancers in Chinese population, and consequently lead to better population survival outcome of lung cancer and more related life years saved.

Finally, there is a concern whether the relationship between the early detection of lung cancer and the survival improvement might be confounded by the lead-time bias or not [41]. As known, to estimate the confounder effect from the lead-time bias, the mortality rate of the disease need look at instead as a gold standard for measuring the early screening and treatment, but not the survival length. Namely, the events of lung cancer-related death during the long-term follow-up should be considered between early and locally advanced stages. Additionally, the most of the lung cancer-related death are resulted from postoperative recurrence or metastatasis. Therefore, a comparison of postoperative recurrence or metastatasis is also meaningful to test the lead-time bias. Torok JA, et al. found, among surgical patients with stage I-III non-small cell lung cancers, the earlier $\mathrm{T}$ stage or $\mathrm{N}$ stage diseases displayed a lower distal metastatasis risk [42]. Furthermore, Wang J, et al. evaluated the natural growth and disease progression of lung cancer through 18F-fluorodeoxyglucose PET/CT, and found the lung cancer appeared rapid tumor volume growth with the double time no more than half a year [43]. Actually, the lead time derived from lung cancer screening might be very limited. Therefore, we guess the the leadtime bias influences little in the lung cancer sceening associated improvement of the population survival.

In a short, by the epidemiological inference, the LDCT screening might be associated with increasing stage I lung cancer and therefore improving population survival outcome. Therefore, regarding the poor population survival outcome, it's necessary to establish nationwide organized screening and surveillance programmes based on LDCT among high-risk population to improve overall survival outcome of lung cancer in China. However, how to translate the experiences of lung cancer screening by LDCT from developed counties to China in a costeffective manner needs to be further investigated. 


\section{MATERIALS AND METHODS}

The proportion of stage I lung cancer in LDCT screening population was retrieved from NLST (U.S.) and NELSON (Europe) trials $[4,5]$. The general proportion of stage I lung cancer in China was retrieved from a rapid meta-analysis with a random effect model (Comprehensive Meta-Analysis 2.0; Biostat, Englewood NJ, USA). The China National Knowledge Infrastructure (CNKI) database was searched during 2012-2014. Only studies based on hospital-based cross-sectional population were included for meta-analysis. The lung cancer mortality and prevalence of China, U.S. and Europe was retrieved from Globocan 2012 fact sheet issued by International Agency for Research on Cancer [44]. Mortality-to-prevalence ratio (MPR) was applied to compare the population survival outcome of lung cancer $[8,45,46]$. The relative ratio (RR) between China and U.S. or Europe was calculated to estimate the differences of stage I disease proportion and population mortality. Two-sided $p$ value less than 0.05 was considered as statistical significance.

\section{Data sharing}

The reference list of included Chinese studies identified from the China National Knowledge Infrastructure (CNKI) database was unpublished. These extra data is available by emailing Dr. Xin- $\mathrm{Zu}$ Chen (chen_xz_wch_scu@126.com).

\section{ACKNOWLEDGEMENT}

This study was granted by the National Natural Science Foundation of China (no. 81301866), and the Outstanding Young Scientific Scholarship Foundation of Sichuan University, from the Fundamental Research Funds for the Central Universities of China (No. 2015SCU04A43). The funders did not play any role in the conception, analyses and writing.

\section{CONFLICTS OF INTEREST}

None declared.

\section{REFERENCES}

1. Guldbrandt LM. The effect of direct referral for fast CT scan in early lung cancer detection in general practice. A clinical, cluster-randomised trial. Dan Med J. 2015; 62.

2. Cheng Y, Jiang T, Zhu M, Li Z, Zhang J, Wang Y, Geng L, Liu J, Shen W, Wang C, Hu Z, Jin G, Ma H et al. Risk assessment models for genetic risk predictors of lung cancer using two-stage replication for Asian and European populations. Oncotarget. 2016 Jul 5. doi: 10.18632/ oncotarget.10403. [Epub ahead of print].
3. Dong J, Hu Z, Wu C, Guo H, Zhou B, Lv J, Lu D, Chen K, Shi Y, Chu M, Wang C, Zhang R, Dai J et al. Association analyses identify multiple new lung cancer susceptibility loci and their interactions with smoking in the Chinese population. Nat Genet. 2012; 44:895-9.

4. National Lung Screening Trial Research Team, Aberle DR, Adams AM, Berg CD, Black WC, Clapp JD, Fagerstrom RM, Gareen IF, Gatsonis C, Marcus PM, Sicks JD. Reduced lung-cancer mortality with low-dose computed tomographic screening. N Engl J Med. 2011; 365:395-409.

5. Horeweg N, Scholten ET, de Jong PA, van der Aalst CM, Weenink C, Lammers JW, Nackaerts K, Vliegenthart R, ten Haaf K, Yousaf-Khan UA, Heuvelmans MA, Thunnissen E, Oudkerk $M$ et al. Detection of lung cancer through lowdose CT screening (NELSON): a prespecified analysis of screening test performance and interval cancers. Lancet Oncol. 2014; 15:1342-50.

6. Li ZY, Luo L, Hu YH, Chen H, Den YK, Tang L, Liu B, Liu D, Zhang XY. Lung cancer screening: a systematic review of clinical practice guidelines. Int J Clin Pract. 2016; 70:20-30.

7. Wang R, Chen XZ. High mortality from hepatic, gastric and esophageal cancers in mainland China: 40 years of experience and development. Clin Res Hepatol Gastroenterol. 2014; 38:751-6.

8. Chen XC, Chen XZ. Epidemiological differences in haematological malignancies between Europe and China. Lancet Oncol. 2014; 15:e471-2.

9. Fan L, Strasser-Weippl K, Li JJ, St Louis J, Finkelstein DM, Yu KD, Chen WQ, Shao ZM, Goss PE. Breast cancer in China. Lancet Oncol. 2014; 15:e279-89.

10. Zhang SW, Chen WQ, Lei ZL, Zou XN, Zhao P. [A report of cancer incidence from 37 cancer registries in China, 2004. Chin Cancer]. [Article in Chinese]. 2008; 17:909-12.

11. Chen WQ, Zhang SW, Kong LZ, Lei ZL, Zhao P. [Cancer mortality report of 34 cancer registries in China, 2004]. [Article in Chinese]. Chin Cancer. 2008; 17:913-6.

12. Zhang SW, Lei ZL, Li GL, Zou XN, Chen WQ, Zhao P. [A report of cancer incidence and mortality from 34 cancer registries in China, 2005]. [Article in Chinese]. Chin Cancer. 2009; 18:973-9.

13. Chen WQ, Zhang SW, Zou XN, Zhao P. Cancer incidence and mortality in china, 2006. Chin J Cancer Res. 2011; 23:3-9.

14. Chen WQ, Zeng HM, Zheng RS, Zhang SW, He J. Cancer incidence and mortality in china, 2007. Chin J Cancer Res. 2012; 24:1-8.

15. Chen WQ, Zheng RS, Zhang SW, Li N, Zhao P, Li GL, Wu LY, He J. Report of incidence and mortality in china cancer registries, 2008. Chin J Cancer Res. 2012; 24:171-80.

16. Chen W, Zheng R, Zhang S, Zhao P, Li G, Wu L, He J. Report of incidence and mortality in China cancer registries, 2009. Chin J Cancer Res. 2013; 25:10-21.

17. Chen W, Zheng R, Zhang S, Zhao P, Zeng H, Zou X, He 
J. Annual report on status of cancer in China, 2010. Chin J Cancer Res. 2014; 26:48-58.

18. Zhang Y, Hong QY, Shi WB, Ou JX, Yang DW, Hu J, Bai CX, Zeng MS, Chen G. [Value of low-dose spiral computed tomography in lung cancer screening]. [Article in Chinese]. Zhonghua Yi Xue Za Zhi. 2013; 93:3011-4.

19. Tang W, Wu N, Huang Y, Wang J, Zhao S, Xu Z, Zhang K, Jiang Y, Cai Q, Zhou L, Li M, Tao D, Liu X et al. [Results of low-dose computed tomography (LDCT) screening for early lung cancer: prevalence in 4690 asymptomatic participants]. [Article in Chinese]. Zhonghua Zhong Liu Za Zhi. 2014; 36:549-54.

20. Lai Y, Shen C, Wang X, Du H, Chen D, Tian L, Zhou X, Che G. Status and perspectives of detection by low-dose computed tomography or computed radiography in surgical patients with lung cancer, based on a five-year study. Thorac Cancer. 2016; 7:111-7.

21. Canadian Task Force on Preventive Health Care. Recommendations on screening for lung cancer. CMAJ. 2016; 188:425-32.

22. Manser R, Lethaby A, Irving LB, Stone C, Byrnes G, Abramson MJ, Campbell D. Screening for lung cancer. Cochrane Database Syst Rev. 2013; 6:CD001991.

23. Zhao SJ, Wu N. Early detection of lung cancer: Low-dose computed tomography screening in China. Thorac Cancer. 2015; 6:385-9.

24. Humphrey LL, Deffebach M, Pappas M, Baumann C, Artis K, Mitchell JP, Zakher B, Fu R, Slatore CG. Screening for lung cancer with low-dose computed tomography: a systematic review to update the US Preventive services task force recommendation. Ann Intern Med. 2013; 159:411-20.

25. Lai Y, Tian L, Fan J, Huang J, Li S, Du H, Che G. [Relationship between Clinical Characteristics and Diagnostic Modes of Hospitalized Surgical Patients with Lung Cancer]. [Article in Chinese]. Zhongguo Fei Ai Za Zhi. 2015; 18:457-61.

26. Zhou Q, Fan Y, Wu N, Huang Y, Wang Y, Li L, Liu J, Wang X, Li W, Qiao Y. Demonstration program of population-based lung cancer screening in China: Rationale and study design. Thorac Cancer. 2014; 5:197-203.

27. Aberle DR, Abtin F, Brown K. Computed tomography screening for lung cancer: has it finally arrived? Implications of the national lung screening trial. J Clin Oncol. 2013; 31:1002-8.

28. Bach PB, Mirkin JN, Oliver TK, Azzoli CG, Berry DA, Brawley OW, Byers T, Colditz GA, Gould MK, Jett JR, Sabichi AL, Smith-Bindman R, Wood DE et al. Benefits and harms of CT screening for lung cancer: a systematic review. JAMA. 2012; 307:2418-29.

29. Cui JW, Li W, Han FJ, Liu YD. Screening for lung cancer using low-dose computed tomography: concerns about the application in low-risk individuals. Transl Lung Cancer Res. 2015; 4:275-86.

30. Patz EF, Jr., Greco E, Gatsonis C, Pinsky P, Kramer
BS, Aberle DR. Lung cancer incidence and mortality in National Lung Screening Trial participants who underwent low-dose CT prevalence screening: a retrospective cohort analysis of a randomised, multicentre, diagnostic screening trial. Lancet Oncol. 2016; 17:590-9.

31. Stang A, Schuler M, Kowall B, Darwiche K, Kuhl H, Jockel KH. Lung Cancer Screening Using Low Dose CT Scanning in Germany. Extrapolation of results from the National Lung Screening Trial. Dtsch Arztebl Int. 2015; 112:637-44.

32. Lei Y, Chen BJ, Zeng L, Li WM. [Application value of lowdose computed tomography for the screening of lung cancer in high-risk group]. [Article in Chinese]. Sichuan Da Xue Xue Bao Yi Xue Ban. 2012; 43:584-7.

33. Roberts H, Walker-Dilks C, Sivjee K, Ung Y, Yasufuku K, Hey A, Lewis N, Lung Cancer Screening Guideline Development G. Screening high-risk populations for lung cancer: guideline recommendations. J Thorac Oncol. 2013; 8:1232-7.

34. Infante M, Cavuto S, Lutman FR, Passera E, Chiarenza M, Chiesa G, Brambilla G, Angeli E, Aranzulla G, Chiti A, Scorsetti M, Navarria P, Cavina R et al. Long-Term Followup Results of the DANTE Trial, a Randomized Study of Lung Cancer Screening with Spiral Computed Tomography. Am J Respir Crit Care Med. 2015; 191:1166-75.

35. Pastorino U, Rossi M, Rosato V, Marchiano A, Sverzellati N, Morosi C, Fabbri A, Galeone C, Negri E, Sozzi G, Pelosi G, La Vecchia C. Annual or biennial CT screening versus observation in heavy smokers: 5-year results of the MILD trial. Eur J Cancer Prev. 2012; 21:308-15.

36. Henschke CI, Yip R, Boffetta P, Markowitz S, Miller A, Hanaoka T, Wu N, Zulueta JJ, Yankelevitz DF, Investigators IE. CT screening for lung cancer: Importance of emphysema for never smokers and smokers. Lung Cancer. 2015; 88:42-7.

37. Jiang L, Jiang S, Lin Y, Yang H, Zhao Z, Xie Z, Lin $\mathrm{Y}$, Long H. Modified inflammation-based score as an independent malignant predictor in patients with pulmonary focal ground-glass opacity: a propensity score matching analysis. Sci Rep. 2016; 6:19105.

38. Wang X, Ma K, Cui J, Chen X, Jin L, Li W. An individual risk prediction model for lung cancer based on a study in a Chinese population. Tumori. 2015; 101:16-23.

39. Ren G, Ye J, Fan Y, Wang J, Sun Z, Jia H, Du X, Hou C, Wang Y, Zhao Y, Zhou Q. [Survey and analysis of awareness of lung cancer prevention and control in a LDCT lung cancer screening project in Tianjin Dagang Oilfield of China]. [Article in Chinese]. Zhongguo Fei Ai Za Zhi. 2014; 17:163-70.

40. Zhou QH, Fan YG, Bu H, Wang Y, Wu N, Huang YC, Wang G, Wang XY, Qiao YL. China national lung cancer screening guideline with low-dose computed tomography (2015 version). Thorac Cancer. 2015; 6:812-8.

41. Gordis L. Epidemiology. Philadelphia: Saunders. 2008; p.318:ISBN 978-1-4160-002-6. 
42. Torok JA, Gu L, Tandberg DJ, Wang X, Harpole DH, Jr., Kelsey CR, Salama JK. Patterns of Distant Metastases After Surgical Management of Non-Small-cell Lung Cancer. Clin Lung Cancer. 2016.

43. Wang J, Mahasittiwat P, Wong KK, Quint LE, Kong FM. Natural growth and disease progression of non-small cell lung cancer evaluated with 18F-fluorodeoxyglucose PET/ CT. Lung Cancer. 2012; 78:51-6.

44. Ferlay J, Soerjomataram I, Ervik M, Dikshit R, Eser S, Mathers C, Rebelo M, Parkin DM, Forman D, Bray F. GLOBOCAN 2012 v1.0, Cancer Incidence and Mortality Worldwide: IARC Cancer Base No. 11 [Internet]. Lyon, France. Available from: http://globocaniarcfr/Pages/fact sheets_populationaspx. 2013:(accessed on 6/4/2015).

45. Chen XZ, Zhang WH, Hu JK. A difficulty in improving population survival outcome of gastric cancer in mainland China: low proportion of early diseases. Med Oncol. 2014; 31:315.

46. Chen $\mathrm{XZ}, \mathrm{Hu} \mathrm{JK}$, Zhou ZG. Importance of organized screening and surveillance for colorectal cancer in China: epidemiological differences from Europe. Eur J Cancer Prev. 2015; 24:459-60. 